\title{
Research on the Strategic Position of Service Industry in the Development of National Economy
}

\author{
Tie Xiaohua \\ Xian International University; Business School, Shaanxi Xi' an 710077, China
}

\begin{abstract}
Keywords: Strategic Position, Service Industry, Development, National Economy
\end{abstract}
\begin{abstract}
Since the policy of economic reform and opening up more than 20 years ago, China has made remarkable achievements in economic development and poverty alleviation. However, past successes do not guarantee the same success in the future. Each stage of economic development has its own unique opportunities and challenges. Whether it can succeed in the future lies in its ability to successfully overcome challenges, seize opportunities and make good use of it. At present, China faces two major challenges: (1) economic globalization leads to increased competitive pressure; (2) reforming the state-owned economy as the dominant economic system and adapting it to the market economic system. Challenges often bring about opportunities. Global competition and economic reforms can promote economic development. Further economic development can enhance confidence and make the Chinese economy more capable of further opening up.
\end{abstract}

\section{The Status of Chinese Service Industry}

The service industry in our country has a long history, but the overall level of development is low. In Chinese service industry, the traditional service industry accounts for the majority in the system, accounting for a relatively high proportion. With the economic development, the population of our country is increasing year by year but less high-quality talents are required. Therefore, most of the services recruited and employed by the service are the labors who are engaged in manual labor. In today's society, many enterprises attach great importance to the service industry. In particular, the development of new service industries has become the current trend, such as network services, telecommunications and so on. At the same time, our country has also made a great investment in the service industry in recent years, increasing its emphasis on the service industry and making great changes. However, there are still many deficiencies in comparison with other countries. The gap so our service industry's room for development is still great. Now the larger global trade of insurance, consulting, finance and other knowledge-based service industries in our country is still in the initial stage of development. Overall, the overall level of Chinese service industry is relatively low.

With the development of economy, there are obvious economic differences between regions. Coastal cities in the eastern region of our country have a faster economic development and service industries have a clear upward trend. However, the economy in the central and western regions is relatively backward Industry is also relatively backward development. In this way, there is a clear geographical difference in the service industries in the region. The good economic development in the eastern part of our country will attract a large influx of a large number of service-oriented personnel and promote the development of the service industries in these regions. Professional service industry professional skills, a mature service system at the same time a wide range of service systems and service methods as well as enterprises are rapidly developing, for example, the development of the financial industry is very good Many, many well-known enterprises in the eastern coast The rapid development of the region in the insurance, communications, finance are steady and rapid development. The development of the region has a very good lead. On the contrary, the economic backwardness in the central and western regions has restricted people's thinking and awareness, and has not been able to attract enterprises to make investments. The investment promotion has been restricted. The service industries in the central and western regions have not been well developed for a long time. As a result, the development of the service industry there has been a regional difference. 


\section{The Characteristics of Chinese Service Industry}

In the 1990s, Chinese service industry showed a "stagflation" picture. In the past 10 years, the service sector lagged behind other economic sectors in terms of its pace of development. On the other hand, the prices of many service industries have risen sharply, much higher than the price increases of industrial and agricultural products. As a result, the relative price of service industry has been up by $17 \%$ in the past 10 years (see Figure 1), while the increase of the service consumer price index (16.8\%) has also doubled the overall consumer price index Rise (7.5\%). In 1998 and 1999, due to the impact of the Asian financial crisis, the growth rate of aggregate demand slowed down. However, the consumer price index of service industries grew at a rate of $10 \%$ every year. The ability of the service sector to raise prices even as demand decreases allows service-sector owners to pay higher wages than their industrial counterparts (see Figure 4), even though the former employers have far less productivity than the latter (See Figure 3). This ability also gives the service industry a higher capital return (profit, see Figure 5). These economic indicators show that the operation of the service sector as a whole can be defined as a monopoly, because typical performance of monopolistic behavior is high price, limited supply and low quality.

\section{The Strategic Development of the Service Industry for the National Economy}

At present, one of the focuses of Chinese economic work is how to reactivate productive investment in enterprises so as to promote healthy economic growth so as to solve the heavy employment pressure and reduce the impact of a large number of laid-off workers on social stability. Efforts to promote the development of the service industry will help to solve this difficult task.

With regard to the reactivation of productive investment, China needs to stimulate technological innovation by devoting more resources to knowledge-innovation activities, including research and development, personnel training and education. This will help increase the added value of industrial products or increase the value chain and make industrial products more market competitive. Accordingly, the financial system needs to provide sufficient funding for technological innovations in the real economy. However, the problem now is that only a very small part of Chinese deposits flow from financial institutions to technological innovation and start-up of new businesses, with the vast majority of funds still locked in traditional forms of investment. With the rapid development of technological progress in the world, it seems that the establishment of a government mechanism to encourage the formation of private venture capital is imminent. Developing capital markets and improving banking services are also top priorities. Developing and expanding the service industry is also of great significance in providing new employment opportunities. As the economic development advances, agriculture will further reduce employment opportunities. However, due to overinvestment in industries, it will be unlikely that industries will absorb more labor because of the time devoted to structural adjustment and technological upgrading. In this way, only the service sector is capable of absorbing employed personnel in the future. In fact, the situation is already the case. For the past 10 years, service has been the only industry that absorbs a large amount of labor, even though it has fallen in the real proportion of the national economy. The share of service workers in the total employed population increased from $16.4 \%$ in 1990 to $23.5 \%$ in 1997 . At the same time, the share of industrialized employed people has been hovering around $15.0 \%$, while that of agricultural employment dropped from $53.4 \%$ in 1990 to $47.6 \%$ in 1997 . Of course, service workers are mainly concentrated in labor-intensive services with low work skills such as restaurants, hotels, tourism and so on. These industries are growing at a much faster rate than knowledge-intensive services that require high work skills.

In the past 20 years, China has achieved great success in its strategy of promoting economic growth by developing an export-oriented economy. This strategy focuses on opening up international markets and attracting foreign technology and capital through foreign-owned companies. However, this strategy, no matter how successful it was before, is not enough to achieve long-term sustainable development without the strategy of developing a domestic market or a domestic industry. Because of 
the difference between China and a small open economy, the vitality of her vast domestic market is decisive for maintaining sustained economic growth. The huge domestic market is a double-edged sword: if the market lacks vitality, it will drag down the entire economy, as evidenced by the stagnant Japanese economy in the past 10 years; on the other hand, it can also provide the economy Development provides a stable source. This advantage is unmatched by small economies that rely solely on economies of scale in the international market. The good performance of the U.S. economy over the past five years is a good example. Therefore, if Chinese economy cannot lead to strong economic growth based on the domestic market, she may lose the momentum of economic growth once the advantages of an outward-oriented economic strategy are exhausted. The problem now is that the vast domestic market in China still cannot be integrated; this is due to the inefficiency and high costs of logistics, transport and communications services as well as administrative barriers that hinder the free movement of goods, people and capital. The Central Government recently introduced the strategy of "developing the west region" and linked Chinese backward areas with more prosperous areas so that backward areas can also share the benefits of economic development. The success of the strategy of "developing the western region" also depends on whether the above-mentioned obstacles in the service area can be eliminated. Therefore, China should focus on developing its own technologies and successfully bring the achievements of its own technologies to the market so as to develop its own high-tech industries. In order to achieve this goal, China needs to devote more money to developing knowledge-intensive services and financial services.

Chinese service industry has developed relatively lately and has not yet become competitive in the international arena. We have to survive in development and develop in a stable manner. In the light of the development trend in recent years and the turning point in the development of the service sector, Although the service industry in our country started late and is still in the process of development, including infrastructure, communication facilities, technical services and the financial industry, etc., the three industries include a large number of industries and have a presence in the service industries. The management of these service industries is also slightly Sentimental. Therefore, both reform and opening up as well as Chinese accession to the WTO are both opportunities for China. At present, our country regards the development of service industry as the main promotion industry and constantly accelerates the change of service industry. This will provide a better platform for the service industry to raise the service industry's position in the national economy of our country.

The service industry includes many industries and categories. Since the service industry exists in all walks of life formally, in the national economy, the service industry can enhance the development of the national economy both in the horizontal and vertical directions through continuous expansion of the scope and width of economic development. Today's China cannot form an integrated system for its management. The reason lies in the fact that many of our country's systems are inadequate and fail to achieve higher efficiency in work such as transportation, communications and logistics management. However, some relevant policies have also been promulgated in our country. For example, our strategy for developing the western region is to link our relatively backward areas with the more developed areas of our country and let the backward areas to share resources and economic interests. However, whether this strategy can be successful depends on whether the barriers to our service industry can be solved. Therefore, our country should pay more attention to our future technological development and personnel training, and must apply our technical achievements to us In fact, we have to promote the steady development of all industries in our country. Therefore, we must introduce and invest funds to develop our financial services industry and our knowledge-based services.

\section{Conclusion}

The service industry belongs to the tertiary industry and plays an increasingly important role in the national industrial structure. In today's society, logistics, transportation, production and sales, tourism, catering and entertainment are all the industries with the most potential for development and fall into the category of tertiary industry in service industry. The development of these industries or industries 
has also greatly enhanced the level of economic development and national economy Development, but also promotes the development and rise of the economic power of the entire country. Obviously, the service industry plays an important role in the process of national economic development. Understanding and analyzing the strategic position of the service industry in the development of the national economy helps to re-examine the development prospect and direction of the service industry and to make it better into the scope of national economic development.

\section{References}

[1] Zhang Shaojie. Traditional service industry on the impact of national economy [J]. Heilongjiang Social Sciences, 2012 (2): 86-87.

[2] LIANG Dongli.Study on the proportion of service industry in national economy [J] .Industrial Economics Research, 2009 (2): 65-67.

[3] Wang Lu, Li An Yu. Business services on the various sectors of the national economy [J]. China Economic and Trade Guide, 2016 (8): 43.

[4] Liu Zifeng. On the strategic status of the circulation industry [J] .Financial and Trade Research .2005 (02)

[5] Feng Zhijian, Xiao Li. Macroeconomic Impact of FDI on Host Country's Economy [J]. City. 2008 (10)

[6] Fan Leilei. The rural market: a new engine of Chinese growth [J]. Farming Science and Technology. 2009 (03) 